This item was submitted to Loughborough's Research Repository by the author.

Items in Figshare are protected by copyright, with all rights reserved, unless otherwise indicated.

\title{
Contingency and action: a comparison of two forms of requesting
}

PLEASE CITE THE PUBLISHED VERSION

http://dx.doi.org/10.1080/08351810802028613

\section{PUBLISHER}

(C) Routledge (Taylor \& Francis)

\section{VERSION}

AM (Accepted Manuscript)

\section{LICENCE}

CC BY-NC-ND 4.0

\section{REPOSITORY RECORD}

Curl, Traci S., and Paul Drew. 2019. "Contingency and Action: A Comparison of Two Forms of Requesting". figshare. https://hdl.handle.net/2134/13229. 
This item was submitted to Loughborough's Institutional Repository (https://dspace.lboro.ac.uk/) by the author and is made available under the following Creative Commons Licence conditions.

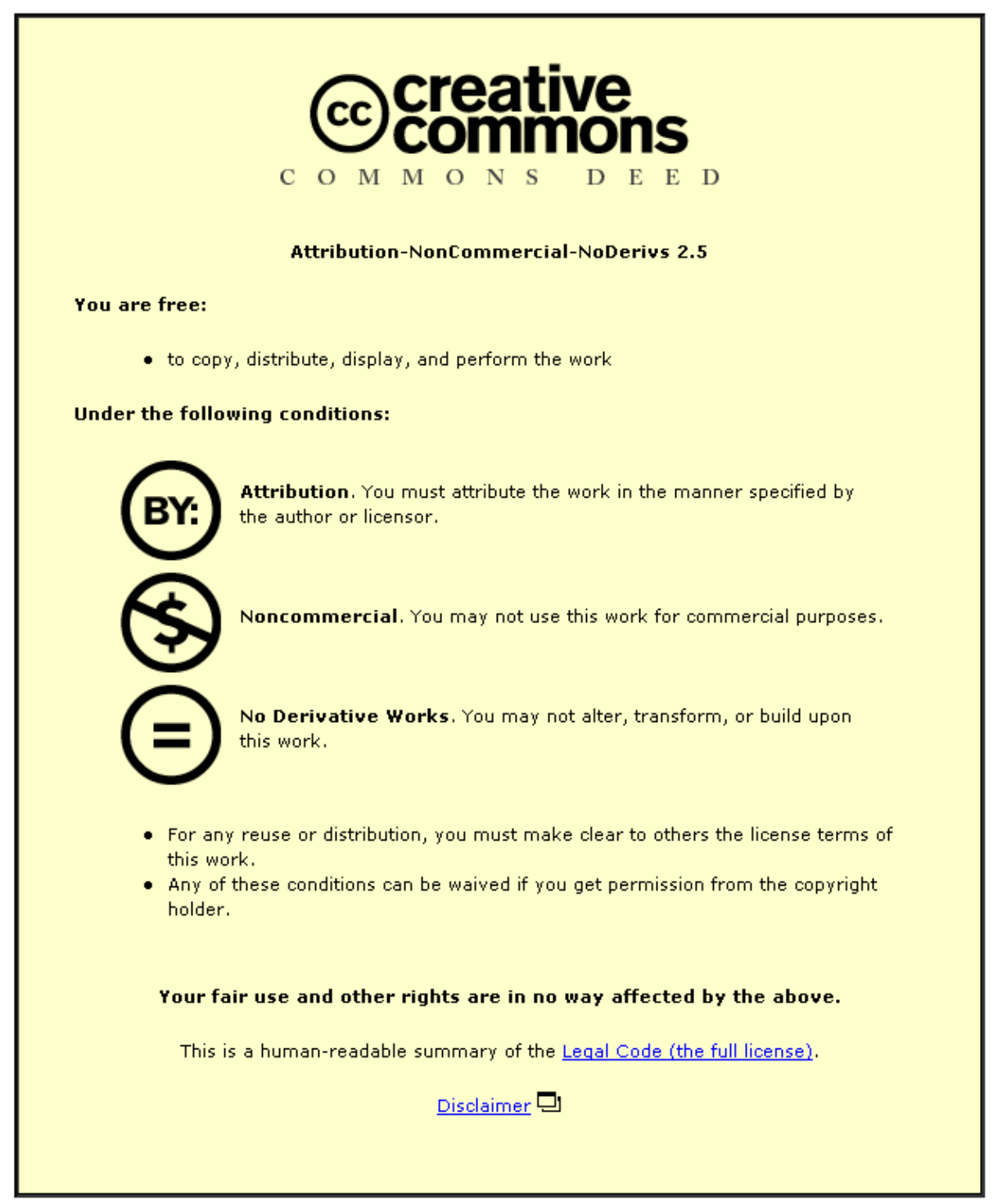

For the full text of this licence, please go to: http://creativecommons.org/licenses/by-nc-nd/2.5/ 
Contingency and action: a comparison of two forms of requesting*

Dr. Traci S. Curl

Department of Language and Linguistic Science

University of York, Heslington, York Y010 5DD

$0190443 \quad 3611$

tsc3@york.ac.uk

Prof Paul Drew

Department of Sociology

University of York, Heslington, York Y010 5DD

01904433056

wpd1@york.ac.uk

This is a report of research undertaken as part of the project Affiliation and disaffiliation in interaction: Language and social cohesion, funded by the British ESRC (grant number RES-00023-0035). Under the terms of a European Science Foundation initiative, the ESRC - whose support is gratefully acknowledged - funded the British part of a 5-nation study co-ordinated by Anna Lindström (University of Uppsala, Sweden). 
Title: Contingency and action: a comparison of two forms of requesting

Running head: Two forms of requesting

Keywords: requests, conversation, syntactic forms, institutional talk, entitlement, contingency

11,020 words

Abstract

This paper explores the syntactic forms speakers use when making requests. An initial investigation of ordinary telephone calls between family and friends, and out-of-hours calls to the doctor, showed a difference in the distribution of modal verbs (e.g., can you. . . ), and requests prefaced by $I$ wonder if... Modals are most common in ordinary conversation, while $I$ wonder if... is most frequent in requests made to the doctor. This distributional difference seemed to be supported by calls from private homes to service organisations, where speakers also formatted requests as $I$ wonder if... . Further investigation of these and other corpora suggests that this distributional pattern is related, not so much with the sociolinguistic speech setting, but rather with speakers' orientations to known or anticipated contingencies associated with their request. The request forms speakers select embody, or display, their understandings of the contingencies associated with the recipient's ability to grant the request. 


\section{Introduction}

Making a request, be it for an object, assistance or information, is a basic and ubiquitous activity in human interaction. Moreover, it is widely acknowledged in the literature that a special sensitivity may be associated with requesting, because it imposes in some fashion on the recipient (e.g., Brown \& Levinson 1987). Requesting may be accomplished through a variety of linguistic forms, including (in English) simply naming the object being requested (e.g., Twenty Marlborough), imperatives such as Pass me the $x$, declaratives such as $I$ need $x$ (you to do $x$ ), through to such forms as would you mind passing me the $x$, Could you do $x$, and Are you using the $x$ ? In this paper we report the findings of an investigation into the different linguistic (lexico-syntactic) forms used to request - and specifically the two forms that we found to be most frequently occurring in our data corpora ranging from ordinary (ie. social, family etc.) interactions (telephone and face-to-face) to emergency calls (out-of-hours calls to the doctor, and emergency calls to the police). These two forms were the interrogative with modal verbs would/could you do $X$ ? and a declarative form in which the modal is prefaced by $I$ was wondering if ( $I$ was wondering if you/I could do $x)$.

The principal findings of our report concern speakers' selections between these two forms, selections that reflect their orientations to their entitlement to make the request, and to the contingencies which may be involved in the recipient granting the request. Since these findings differ, in a number of respects, from those reported in the literature to date, it will be worth beginning by reviewing what have been the most salient themes in the research literature on requesting.

This literature has, in one way or another, focused largely on the relative directness with which requests are made, or constructed. For instance, some of the earlier forms illustrated above, such as naming an object, imperatives and I need you to.., seem direct; whereas forms such as I was wondering if.. and Are you using the $x$ might be considered rather indirect ways 
of asking for something. Given the association between requesting and imposing on a recipient, and also the interest (especially in the conversation analytic literature) on managing actions so as to avoid dispreferred responses, in this case the rejection of a request (eg. Schegloff 1987a), the literature has focused particularly on indirect forms, or the indirectness with which speakers manage request sequences. There are perhaps three research traditions/perspectives that have most conspicuously explored the indirectness of request forms.

Given the supposed indirectness of the relation between, on the one hand, the surface form and literal meaning of some utterances, and on the other hand their illocutionary force (as it is generally termed: Austin 1962, Searle 1975) as requesting, one theme in the literature has been the inferencing rules by which recipients understand the request which is embedded in or communicated through an utterance. At the most general level, it was, after all, Grice's objective to show how saying one thing could entail communicating another, through the operation of certain general principles of conversation (Grice 1975). More specifically about requesting, Searle's object of enquiry was how "a speaker may utter a sentence and mean what he says and also mean another illocution with a different propositional content. For example, a speaker may utter the sentence can you reach the salt? and mean it not merely as a question but as a request to pass the salt." (Searle 1975: 59/60). His answer was that each type of illocutionary act has a set of conditions - 'felicity conditions' which are necessary for the performance of the act; by which searle meant, the appropriate or correct understanding of the action which was 'intended' by a form of words. Hence the literature on indirect speech acts is concerned to formulate the conditions (inferencing rules) that need to be met in constructing an utterance, to enable the inference to be made that the speaker is requesting. This has been developed in subsequent studies of the processes through which indirect request forms are understood (eg. Clark 1979, Clark and Schunk 1980; Francik and Clark 1985; Gibbs 2002). However, the focus on inferencing rules and processes provides little information about how and why speakers select a 
particular request form, from among the variety of forms that are available which is the object of our enquiry here.

The second and perhaps the most influential research tradition relating to the indirectness of requesting is politeness theory, stemming from Brown and Levinson's proposal (following Goffman 1967) that politeness, deference and tact, embodied in language and linguistic forms, underpin the orderliness of social interaction, and therefore are part of the "foundations of human social life and interaction." (Brown and Levinson 1987:1). At the heart of Brown and Levinson's politeness theory is the explanation that speakers select indirect forms of requests as a means to avoid 'negative face'; and that there is a range, or scale, or politeness strategies embodied in the grammatical forms of (indirect) requests. Politeness theory proposes connections between negative face, specifically ensuring the other's freedom from imposition; deference and social distance (as reflected in identities and relationships of power, institutional authority, affective ties and the like); and a scale of politeness, according to which speakers select from among a range of forms for doing a 'face threatening action', i.e., request; or even to avoid doing the action altogether (Brown and Levinson 1987: 131). This is not the place to provide a summary or overview of Brown and Levinson's theory, and its subsequent development (for a particularly clear overview, see watts 2003). But because it is the only perspective which truly attempts in any systematic fashion to account for the production of a request form (in contrast to the focus on how inferences may be drawn about actions intended or implied by a literal meaning) (Watts 2003), which is, again, the focus of our study, it will be worth reviewing some of the limitations which have been highlighted in the literature, and some of the claims arising from politeness theory which do not appear to be supported by our findings.

First, claims about the relative politeness of an utterance seem to be based on intuitive judgements about a particular form of words (eg. "For an illustration of some more specific principles we may turn to the following intuitive ranking (obtained from native speakers) of indirect requests for a 
cigarette in Tamil," Brown and Levinson 1987: 143). Furthermore, these claims suppose that certain lexico-syntactic forms are intrinsically polite, or more or less polite than others. Watts, in particular, has shown that this is not the case. He demonstrates that such claims rest on abstracting utterances from their interactional and sequential contexts. The same form or construction can have different implications as regards 'politeness' when considered in different interactional circumstances and in different sequences of interaction differences which are further reflected in, indeed produced through, different prosodic realisations of an utterance form (Watts 2003, especially ch.7). However, the interactional circumstances in which an utterance is produced is generally not considered in studies which either use 'real' examples of spoken utterances, but abstracted from the surrounding talk/interaction (Blum-Kulka 1987); or they use fabricated examples (e.g., Clark 1979, Francik and Clark 1985); Brown and Levinson analyse both abstracted and fabricated examples. For further critiques that politeness judgements have been made on utterance forms stripped from their interactional contexts, see also Ervin-Tripp 1976 and Upadhyay 2003

Second, the only real basis for assessing the potential (negative) face threat of an utterance (the imposition it places on the recipient) appears to be social distance, and specifically what are regarded as institutional role relationships, and the relations of relative deference associated with those roles. So that the selection of a given form, or politeness strategy, is explained in terms of quite conventional sociolinguistic identities. "Brown and Levinson's 'sociological' variables are taken to be static social entities that determine the degree of politeness offered. In particular, power and social distance become reified, taking on an existence outside the social sphere of the interactants rather than being themselves constructed...through the interaction itself" (Watts 2003: 114). As further evidence in support of Watts's point, the findings we report below a) do not show any correspondence between request forms and institutional or other identities (e.g., the modal could you is used in social conversation between son and mother, and in some emergency calls to the 
doctor); and b) demonstrate that different forms may be used by the same participants, in the same interaction (eg. during a phone call between family members), but according to different interactional circumstances which relate to the salient contingencies which may be involved in granting the request.

Third, there is a more general matter of whether what is captured in politeness theory is really 'politeness'. Since this is tangential to our enquiry, we will restrict ourselves to noting only that research shows that the inclusion of please, putatively one of the most 'obvious' markers of politeness (again, presumably according to the intuitive judgements of native informants), may make an utterance not more polite, but rather more insistent (e.g., ErvinTripp 1976 and watts 2003:ch.7). For instance, in his study of children's use of please, wootton provides a nuanced account of how please (in turn initial position) can be deployed in a variety of sequential circumstances, including those in which "the child is publicly acknowledging/exposing that what she now wants is in tension with what the parent is in the course of getting underway" (Wootton 2005:200). This is more sophisticated, and empirical, than searle's point, which nevertheless is relevant here, that "When please is added to one of these sentences, it explicitly and literally marks the primary illocutionary point of the utterance as directive, even though the literal meaning of the rest of the sentence is not directive," Searle 1975:68.

Finally, the strategies associated with 'negative politeness' (referring to actions such as requests which threaten the negative face of the recipient) rest initially on a distinction between being direct ('on the record'), and being indirect; and then on distinctions between linguistic forms or constructions which are taken to represent different or relative degrees of politeness. So that a speaker has initially to choose between being direct (Brown and Levinson 1987:130), through selecting a request form such as would you do $X$; or being indirect, through a construction such as Can/could you do $X$, taken to be indirect on the grounds that it asks only whether the recipient is able to do what is requested, not whether he/she will do it (Brown and Levinson 1987:129-142). ${ }^{1}$ According to this, indirect constructions of the form Can/could 
you do $X$ and $I$ wonder if you could do $X$ are equally indirect forms of requesting, through their being question frames which 'reduce pressure' on the recipients (sharing as they do the same modality; for more on modality and politeness, see Perkins 1983). In taxonomies of politeness strategies, I wonder if.. constructions are categorised as 'playing down' or toning down the request, ${ }^{2}$ and could you... is categorised as a 'consultative device' (House and Kasper 1981, watts 2003: 183). Essentially, though, they are treated as equivalent forms of indirectness. But our findings reported below do not support the distinction made (in politeness theory and elsewhere) between direct and putatively indirect forms, between would you and could you; neither do our findings support treating could you and I wonder if you could as equivalently indirect forms. We could find no difference between speakers' selection between the modal constructions would you and could you. These appear to be used in precisely equivalent interactional circumstances, in identical sequential environments. On the other hand, we have identified a key and quite fundamental difference between the interactional circumstances in which speakers select either could you or I wonder if.

The third research tradition/perspective from which requesting (and indirectness) has been viewed is Conversation Analysis (CA). Whereas politeness theory is, as we have said, principally a 'production model', in contrast CA has focused on the sequences which are initiated by requests, and especially on the sequential and turn design features associated with the 'preferred' response of granting, and the 'dispreferred' response of rejection. The literature and findings concerning requests, invitations and the like being first parts of adjacency pairs, to which 'positive' responses (acceptances and the like) are preferred and 'negative' responses (rejections, declinations etc.) dispreferred, is too well known to bear repeating here (but see Heritage 1984: 265-280, Sacks 1992:521-569, Schegloff 1988b). However, in focusing on (request) sequences and especially responses to initial actions, CA research has mostly concerned the sequential management of requests and the design of responses: it has (with one notable exception; Wootton 1981 and 2005) had less to say about the form or 
construction of the initial action (the request) itself, and on the sequential and other interactional factors which may play a part in the selection of one rather than another form. 'Indirectness' in requesting, associated with the dispreferred character of a possible rejection, has been shown to be a feature of the sequential management of talk leading up to a possible request (presequences: e.g., Schegloff 1988a). This has metastasised into regarding requests themselves as 'dispreferred' actions, which is congruent with negative face (and requests being face threatening actions) in politeness theory. ${ }^{3}$ The point we wish to highlight, however, is that research in $\mathrm{CA}$, together with other interactional approaches, has not focused much on the design of turns in which speakers make requests. Given the alternative constructions (noted above) available to make a request, there has been little empirical investigation into the interactional circumstances or environments in which speakers select one form rather than another. In other words, with the exception of some recent studies which we will discuss in our conclusion, in order to compare with our findings, there has been little enquiry into "Why that (form) now?"

In what follows, we report the findings of an investigation which began by examining the distributional patterns of what are in our data the two most commonly used forms for requesting, would/could you.. and I wonder if.., and then related these patterns to the interactional circumstances in which they were selected. We provide an account for speaker selection of one form rather than another, in terms of speakers' orientations to their entitlement to ask, and the contingencies which may be associated with granting the request (eg. doing what is asked).

In comparing the requests found in a corpus of recorded telephone calls made in private homes to those requests made in after-hours calls to an doctor's office, we find a striking division: the former are generally produced with modal verbs or imperatives, while the latter requests that the doctor visit or provide help are often prefaced with I wonder if. It seemed as though it might be the case that modal verbs (Can you. . . , Could you. . . etc.) are used in so-called ordinary conversation; whilst I wonder if you could. . . is used in 
so-called institutional interactions, for example in interactions between professionals and lay persons, as in our corpus of calls to the doctor. However, further investigation of this hypothesis demonstrates that this distributional variation cannot be attributed solely or directly to intimate vs institutional talk, as sociolinguistic contexts. For instance, we do find cases (albeit very few) of $I$ wonder if and related contingent forms in the everyday requests, and $I$ wonder if requests are nearly absent in some other institutional databases of requests. So, we offer an account of how the design of turns used to make requests is affected by speakers' understandings of the contingencies surrounding the granting of the request, and the entitlement of the speaker to make a particular request of a particular hearer. This account shows how linguistic structures are resources though which actions are managed, and social identities mobilized in interaction. In the following section we provide an overview of our methodology and describe the data used in the study. In Section 3, we give the particulars of the predominant forms of requests found in each of the collections. Section 4 shows how the design of requests is related to speakers' assessment of their entitlement to the requested object/activity and of the contingencies surrounding its granting. We conclude with a discussion of how this work furthers our understanding of the reciprocal relationship between social and linguistic structure.

\section{DATA AND METHODOLOGY}

This study is informed by the methodology of conversation analysis (for an overview see Drew 2005), insofar as we are concerned with describing and analyzing the linguistic design and sequential placement of turns at talk. Close attention to the design of a turn reveals the speaker's analysis of the activity s/he is pursuing. We do not attempt nor advocate hypothesizing about the psychological state of the speaker and we do not claim access to speakers' inner mental states. We do, however, investigate what can be learned from the speaker's choice of linguistic expression or form - why that form? why in that 
position? - especially when that form in that position is a recurrent systematic feature in many different interactions.

The corpora used in this study are all recordings of telephone calls made within Great Britain within the last 25 years. Although a larger set of corpora inform an ongoing investigation into the form and use of requests, including calls to the police and various face-to-face interactions (see Curl, Drew and ogden forthcoming), in this report we focus on a comparison of the request forms found in just two of these corpora. This allows us to focus on potential differences in request forms used in mundane, everyday interactions with those occurring in institutional settings.

We collected approximately $9 \odot$ instances of requests for an object (e.g., to bring a letter) or assistance (e.g., passing along a message) from a corpus of telephone calls recorded by private citizens on their home telephones. These may, and do, contain calls not only with acquaintances, friends and family members but also to various businesses and service providers. Throughout the paper, we refer to this collection as the 'everyday' calls. To this, we compare a collection of requests made in 59 after-hours telephone calls to a British primary care physician's practice (known in Britain as GPs). ${ }^{4}$ These calls are made by patients, or more commonly on behalf of patients, whose problems callers regard as sufficiently urgent to require immediate attention. Linguistic expressions of requests occur in just under one half of the calls recorded; otherwise, callers simply describe a medical problem. Undoubtedly a request for assistance is implicit in such problem descriptions, but it is left to the doctor to interpret just what type of care is needed (see Drew (2006) for more information on the production and handling of these calls). In this study, we consider mainly those calls in which an identifiable, overt request is produced (approximately half of the calls). We refer to this collection as the afterhours medical calls. 
Before turning to the comparison of the everyday and after-hours medical request collections, we first provide an overview of the formats in which requests are produced. We identified requests as turns at talk in which a speaker asks the recipient to perform a specific activity, or asks for the transfer of an object from one place or person to another. Our chosen methodology is qualitative; some of the problems in doing quantified analyses of naturally-occurring data are detailed in Schegloff (1993) and Curl (2006). Therefore, we present our observations as generalizations drawn from an analysis of all the instances in the collections, and offer several illustrative examples rather than a tabular or numerical breakdown. Where appropriate, approximate numbers are provided to give an idea of the distributions we are working with, which we hope the reader will take not as the outcome of our analysis, but rather an input to it.

\subsection{Requests in everyday calls}

As it happens, many (though not all) of the requests in the collection of everyday calls are done at the opening of the call, as in Example 1 . The syntactic format of the requests shown here, with a modal verb, is one of the most common forms, accounting for more than half of the requests in the collection.

(1) Field S088:2:8:1

1 Les: Hello:?

$2 \quad(0.3)$

3 Gor: It's Gordon.

4 Les: .hhhh oh Gordon. Shall I ring you back darling,

5 Gor: Uh:: no y- I don't think you can,

$6 \quad(0.3)$

$\rightarrow 7$ Gor: But uh: just to $(\Theta .3)$ say $($.$) could you bring up a$

8 letter.

$9 \quad($. 
10 Gor: When you come up,

(2) Heritage 1:3:3

1 Ile: .uhhhh .mpt $W^{\prime} l$ look uh: :m

$2 \quad(0.8)$

3 Ile: .mk Kah- eh t'morrow's Fri:day $\underline{i} s n[' t$ it.h

4 Lis: [Yah.

$\rightarrow 5$ Ile: .hhh Uh:m: (.) no:w u- can you come over in the

6 morning? or the afternoon be[cause

7 Lis: $\quad\left[\mathrm{I}:{ }^{\prime} l 1\right.$ have to consult

$8 \quad($ Siiim)

9 Ile: eeYah. Because I'll tell you what I:- uh .hh I've got

$10 \quad$ Meals on wheels in the morning

(3)Field S088:2:9

1 MsJ: She says oh: I don't know p'raps they've gone off for

2 the weeken:d.=

$\rightarrow 3$ Les: =No: : . №: : . . hhh We:ll- $(0.2)$ c-Could $\uparrow$ you (.) ask'er

4 if she c'd ring agai:n it's uhr-er- when she gets in,

5 MsJ: Ye:[s.[Yea [h I'll

6 Les: $\quad[. h[h h$ [Only $\uparrow$ Gordon's jus' $\downarrow$ pho:ned 'n 'ee wanted to

$7 \quad$ know how she $\downarrow$ wa:s

(4) Rahman: A: 1: IM: (3)

1 Mat: Hel'Redc'r five o'six one?,

2 Ida: Eh- Matthew: it's only me again,

3 Mat: Yeh, h

$\rightarrow 4$ Ida: Will yih just tell Mummy (0.2) eh: that my furnitures have

5 arri:ved?, 
7 Mat: [Yeh,

8 Ida: [If she happens tuh be passing Barker en Stone'ou:se?

9 Mat: Yeh,

10 Ida: e-Dehr in there. A(h)lright?,

11 Mat: okay,

About two-thirds of the collected requests are done with modal verbs. 5 "Could" in examples 1 and 3, "can" in example 2, and "will" in example 4 are all modal auxiliaries, which, when teamed with a matrix or main verb, function to question the recipient's ability or willingness (or both) to perform the requested activity: "could you bring" and "could you ask"; "can you come over"; "will you just tell Mummy". The use of modal verbs to make requests is not in itself particularly interesting. However, what is remarkable is how the form of these requests differ from the request formats used in the after-hours medical corpus. Requests made with modal verbs -- the request type that dominates in the everyday collection -- are nearly absent from the medical calls. Furthermore, the request format that dominates in the medical collection is nearly absent from the everyday collection. We turn now to an exemplification of that request format, the 'I wonder' preface.

\subsection{Requests in after-hours medical calls}

Generally, calls in the medical corpus open with a description of a problem, e.g., 'my wife has just fainted' (Call 1:1:13) or 'I've got very bad pains in my chest' (Call 2:1:10). Such descriptions elicit questioning by the doctor, who then either offers to visit or recommends some kind of self-treatment or monitoring. The purpose of these calls might be glossed broadly as requesting a visit; in fact many callers display an orientation to this by opening with a declaration that they are 'just ringing for advice', thereby countering the expectation that they are requesting a visit. Some callers, however, do make more or less explicit requests, ranging from 'I wonder if you could give me some 
advice' (Call 1:1:5) to 'so is there anything you can do for me?' (Call 1:1:2). Request formulations prefaced by 'I wonder' are the most common type of requesting turn, accounting for half of the first formulations of a request. ${ }^{6}$ This I wonder preface is employed whether callers are requesting a visit, advice, or help, as shown in the examples below.

(5) $2: 1: 9$

1 Doc: .hhHello:

$\rightarrow 2$ Clr: Hello ehr. I'm wonderin' if a doctor could call and see ((name omitted)) please

(6) $1: 1: 12$

1 Doc: hello,

$\rightarrow 2$ Clr: mt! Hello, I wonder if you could give me some advice,

(7) $1: 2: 2$

1 Doc: . hhHello:

$2 \quad($.

$\rightarrow 3$ Clr: Hello, I wonder if you could help me. Ehm: my little

4 boy's just been stung by a wasp on 'is thumb. What

5 d'ya do:?

The most common pattern, as shown in these examples, is for the caller to move immediately to the $I$ wonder-prefaced request after the exchange of greetings ${ }^{7}$. The use of I wonder prefaces as the predominant form for linguistically explicit requests in the collection of medical calls stands in stark opposition to the predominant form of requests found in the everyday collection - modal verbs. Distributionally, then, we have evidence for a difference in the use of the I wonder prefaces and modal verbs to make requests. At first blush, it appears that the choice of form might be explained solely by the institutionality of the interaction -- that the sociolinguistic context, 
including the relationship between the speakers, triggers the use of either a modal verb or an I wonder-prefaced request. However, cases of 'institutional' interactions where modal verbs are used to make requests, and everyday or 'intimate' interactions where requests are done with $I$ wonder prefaces, needed to be explained as well. Closer analysis of all cases of requests makes the contextual triggering argument look far too simple.

4 THE USE OF DIFFERENT REQUEST FORMATS TO DISPLAY ENTITLEMENT AND ACKNOWLEDGE CONTINGENCIES

Examination of both $I$ wonder-prefaced and modal verb requests in each collection reveals that the different formats are used by speakers to display or claim entitlement to make a request, and to display (or conversely, not acknowledge) an understanding of the contingencies associated with granting their requests. In this section, we first examine the requests in calls to the doctor's office which are made without I wonder prefaces.

(8) Call 1:2:12

1 Doc: Hel:10:,

2 Clr: Hel:lo, is tha' du-doctor

3 Doc: Yes, Doctor ((omitted)) speaki:ng,

$\rightarrow 4$ Clr: i:i:(Yeah) couldja's (call'd) an' see my wife please,

$5 \quad . h[h$

6 Doc: [Yes: .

7 Clr: She's breathless. She can't .hh get 'er breath .hh

(9)Call 1:1:15

1 Doc: ehhm Hello:, Doctor ((omitted)) speaking,

$\rightarrow 2$ Clr: Yeah, hello. I:'d like a doctor sent out please to:

$3 \quad$ Mister ( (omitted))

4 Doc: $Y(h) e s$, what's the problem. 
5 Clr: E:h:if: he was: just released from hospital on:

6 Tuesday or Wen:sday,

7 Doc: R:ight,

8 Clr: An: eh: he been takin' pains in his stomach and

9 they've took him in (tay:) an put 'em on a bag you

10 know to let him do his toilet and that. 'Cause he

11 couldn't: do the $t$ - eh: pass a water

$12 \mathrm{Clr}$ : A[n:d eh: well he's been taking severe pains again in

13 Doc: [Yes,

$14 \mathrm{Clr}$ : his stomach

15 Doc: Yes,

$16 \mathrm{Clr}$ : and hh well he's not been to the toilet in a couple

17 days either

(10)Call 1:2:1

1 Clr: Well, t.h I had Doctor Lancaster out here e- en- (1.7)

2 Thursday night,

$3 \quad(0.4)$

4 Doc: Ye:s,

5 Clr: At's- the wife. An'- she's-doubled up in pain.hh

6 Doc: Yes,

7 Clr: An'- I mean- really in pain. .hh Now she's sweat'in,

$8 \quad$.hh she's sick every ten minutes,

$9 \quad(1.0)$

10 Doc: Ri:ght,

11 Clr: An'- I (haven' exactly) what's wrong.

$12(0.4)$

13 Doc: Wha[t did

$14 \mathrm{Clr}$ : [She didn' be wantin' a doctor, .hh but- I'm afraid

$\rightarrow 15$ I'm- I'm sorry, but I'm gonna have to call you out 
In each of these calls, the caller portrays the medical problem as very serious: breathing trouble, post-operative complications, and severe, unremitting pain for which medical intervention has already been sought and received $^{8}$. In the way they describe the symptoms (Drew 2006), these callers display no doubt as to whether the condition they are calling about is serious enough to warrant a visit. And it is in just these extreme situations that callers eschew the $I$ wonder-prefaced request forms and instead opt for "couldja", "I'd like a doctor sent out please", and "I'm sorry but I'm gonna have to call you out". In the talk both before and after these requests, the speakers display their entitlement to the requested action - and they use modal verbs to make these requests, rather than the $I$ wonder preface.

Now we can turn to some cases in the everyday collection where speakers employ I wonder-prefaced forms. It should be noted that I wonder-prefaced requests in the everyday collection do occur predominantly in requests made in calls made to institutions -- examples 10 and 11 are calls made to an optician and a bookshop, respectively. What can be seen, however, is that the $I$ wonder preface is not simply a format reserved for interactions with institutions, but instead is a way to display one's lack of entitlement to having a request granted, or one's awareness of the contingencies surrounding the granting of a request.

(11) Rahman:1:2:JT 11

1 Dsk: Hello Goodzwin,

2 Jen: Ehm good morning. eh it's Missiz Rah:man here, I

3 ca:lled in on Thursday: to see: if uh I could make an

4 appointment $t^{\prime}$ see Mister Fawcett,

$5 \quad(1.2)$

$\rightarrow 6$ Jen: An- I haven't heard anything'n I was wondering if:

7 uh:m > (it was possible)< to see him:(um) one day next

8 week, 
(12) Field:2:2:1((opening unrecorded))

1 Les: ... and ordered a boo:k [.hhh and you said you'd ho:ld

2 Jon: $\quad$ [yeah

3 Les: it for me

4 Les: And (.) I was supposed to be coming in around Easter

$\rightarrow 5$ well I haven't managed to get $\underline{i}: \mathrm{n}$ a:nd I wonder if you

6 could se:nd it to me if you've still go:t it

These $I$-wonder prefaced requests are a means by which speakers can display their requests as contingent upon knowing and following the proper procedures and practices. In example 11, the "I was wondering if" preface displays Jenny's awareness of the possibility that $\mathrm{Mr}$. Fawcett may not be available to see her. This possibility is alluded to in the opening of the call, in which Jenny describes a prior attempt to make an appointment, a request to which she has still "not heard anything". In example 12, the I wonder-prefaced request suggests a change of plan, from one settled originally (Lesley coming to pick up a book) to one that suits her now (them sending it to her). 'Wondering if' the shop could send the book avoids making a claim to know that they can, or will, or do send books by mail, assumptions which would be conveyed by e.g., 'I'd like you to send it' or 'so could you send it'. Lesley even supplies one of the contingencies that might prevent her request from being granted: “if you've still got it".

In example 13, the same speaker (Lesley) requests another change of plans, this time related to the scheduled delivery of an order. In this example, there is an even clearer display of the speaker's awareness of the contingencies surrounding the granting of the request.

(13) Field:1:3

1 Les: .hh Mister Bathwick (.) uh:m I did ask if you could do

2 me an order on Thu:rsday if I came in an'got it

3 ready:, 


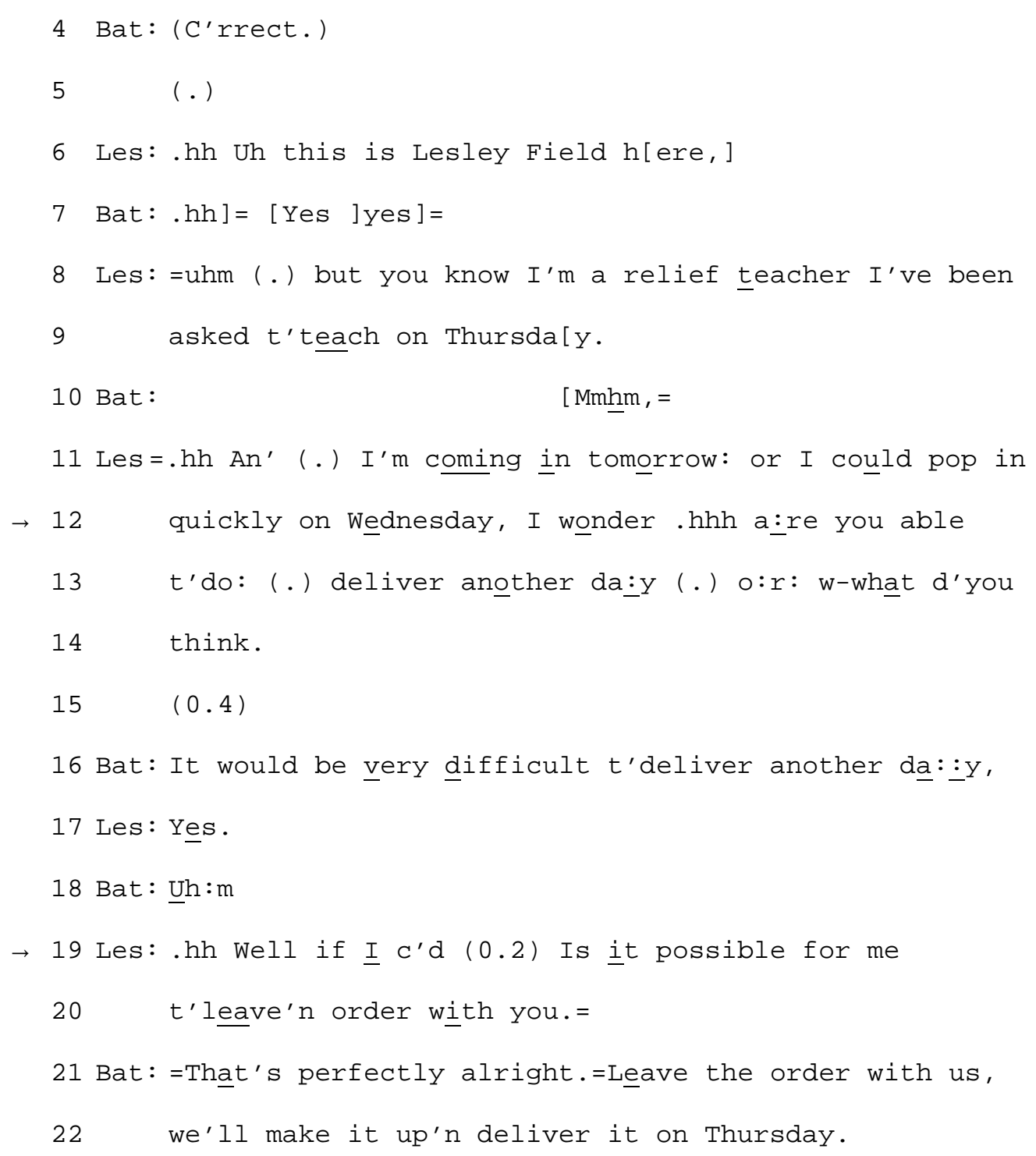

Before making any request, Lesley displays her lack of knowledge of the store's procedures for getting orders ready and making deliveries (see lines 1-3 and 1112). By providing alternatives, Lesley displays her awareness of the contingencies surrounding the granting of her request - she can come in tomorrow, or Wednesday, and she doesn't specify what other day the delivery could be made but instead leaves this up to Bathwick's judgement. Also, like Jenny in example 11 line 7, she makes explicit reference to the possibility of having her request granted - note her repair and reformulation "if I could (0.2) is it possible..." (line 19).

Thus, we can see that in the talk surrounding these $I$ wonder-prefaced requests, speakers avoid displays of entitlement to the requested objects or 
actions. They instead show that they are not making any presumptions, that they do not know if a particular course of action is the appropriate one: they 'wonder if' such-and-such can be done, if it is 'possible'. These forms stand in contrast to modal verbs, the more frequent request forms in this collection. Modals are used to display speakers' assessment of their entitlement to the object of the request. Sometimes, the grounds of this entitlement are displayed prior to or within the request itself, as shown in example 14.

(14) Field:May88:2:3

1 Ste: $\uparrow \underline{\text { Could }}$ you a: :sk Skị:p if-.hmh[at- when you go: to

2 Les: $\quad[. p . k$

$\rightarrow 3$ Ste: this meeting tomorrow .hm could he give Geoff:

$4 \quad$ Haldan's a pologies through sickness?

$5 \quad($.

6 Les: $\uparrow$ Ye $:$ s: . Yes.

By inserting "when you go to the meeting tomorrow", the speaker (Steve) treats that as being the only relevant contingency; that since they are (or skip is; note the change from "you" to "he", lines 1 and 3) going to the meeting, granting his request is unproblematic (i.e. there are no other conditions for granting his request).

The same can be seen in example 1, (repeated below) in which Gordon requests that his mother bring him a letter when she comes to visit.

(1') Field S088:2:8:1

1 Les: Hello:?

$2 \quad(\odot .3)$

3 Gor: It's Gordon.

4 Les: .hhhh oh Gordon. Shall I ring you back darling,

5 Gor: Uh: : no y- I don't think you can,

6 $(\odot .3)$ 
$\rightarrow 7$ Gor: But uh: just to ( $\odot .3)$ say (.) could you bring up a

8 letter.

$9 \quad($.

10 Gor: When you come up,

By mentioning his mother's upcoming visit (line 10, "when you come up), Gordon marks the delivery method for the letter as a known contingency. In this way, he claims entitlement to having his request granted - he is not requesting a special trip to bring the letter, and is instead pointing out the simplicity with which his request can be granted. The I wonder-prefaced form could have been used here; one can easily imagine the substitution of 'I wonder if you could bring' for "could you bring". The important fact, however, is that this is not what was said. It is not simply the environment or context of a requesting activity that triggers the use of a particular form: by using - or not using an I wonder preface, speakers can display and thereby claim differing degrees of entitlement. The actual conditions of use of modal verbs and imperatives vs. I wonder-prefaced requests coincide with and are partly constitutive of speakers' displays of entitlement, and it is the $I$ wonder-prefaced requests (as well as those questioning the possibility of an action), that display speakers' awareness of certain requests as having contingencies that they cannot anticipate.

In the following sequence of calls, we see an exquisite orientation to the claiming of entitlement and ways of displaying awareness of the contingencies of a request expressed through the speakers' choice of request forms. The first (example 15) is from an elderly mother to her middle-aged son, and the next (example 16) from the son to a doctor's office (not the same doctor as in the after-hours medical corpus).

(15) Heritage III:1:2

1 Dor: I want you to telephone $(\odot .3)$ the clinic tomorrow,

$2 \quad(0.9)$ and uh speak to: $(0.2)$ Doctor Pemberton's (0.3) 
$4(0.3)$ a very ba:d (.) hand.

6 Dor: End uh: (0.7) it's all swollen and (0.3) very (.) hot.

$7 \quad(0.4)$ eh: en I do: $n^{\prime} t$ want (any more pills). But (.)

$\rightarrow \quad$ can'e: (0.3) give ()$\cdot(0.3)$ eh-ah- some idea of what

$9 \quad(0.2)$ I c'n bu:y in the way of a (pomage).

10

$(1.0)$

11 Edg: Awright which ha:nd is it.

(16) Heritage III:1:4

1 Edg: Uh:m: (0.3) my mother phoned the other da:y she's

2 staying with: a: uh a daughter of hers in Amersham:

$3(0.4)$ to sa:y that am: (.) hh (०.3) she's having a

4 problem: u-with uh her right ha: :nd, (0.3) uh it is:

5 terribly swollen en rather painful particu'ly the

6 thu: $\mathrm{mb}::$.

$7 \quad(0.7)$

8 Edg: Uh: now (. ) uh y-you you $w^{\prime} l$ remember $p^{\prime}$ haps thet

9 she's had a circulat'ry problem for some ti:me.

$10 \quad(0.4)$

11 Edg: Uh: : and she is takin:g uh: some pi:ll:s which: Doctor

12 Pemberton prescribed for her a few weeks ago: for a

13 (.) fo:r uh:m hhh a: problem she had in one of her

14 feet.

$15 \quad(0.5)$

$\rightarrow 16$ Edg: Uh::m (0.2) Now she is wondering whether the doctor

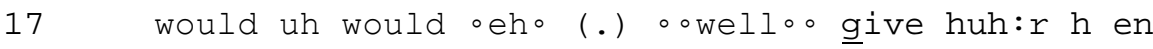

18 indication of uhm: : (.) hh of a-a-a a sohrt of: uh

19 medicine thet she can bu:y from: the chemist. She

20 doesn't want any more pills. 
$21(0.6)$

$\rightarrow 22 \mathrm{Edg}:$ If this is opossible.

23

24 Edg: Ah:m: I-I'm thinking of'n ointment perhaps: .

In example 15, Dorothy phones her son Edgar and asks him to call her doctor and get a recommendation of a medicine for her "bad hand". She displays no orientation to whether or not he can, or wants to, thus displaying her request as not subject to any contingencies. The request she tells him to make of the doctor is similarly devoid of any explicit recognition of any contingency. She does not ask if it would be possible, nor does she 'wonder if he could'. When Edgar calls the doctor, however, this is what he reports her as having said: "she is wondering whether the doctor would..." (line 16).

Here, Dorothy claims and displays her entitlement to make a request of Edgar by her choice of linguistic expression, thus perhaps mobilizing her social identity as a mother. In Edgar's call to the doctor, however, (he is actually speaking with the receptionist here), he displays a lack of entitlement - he, on behalf of his mother, displays himself as a non-expert, someone who is not sure what to ask for, or even if it is permissible to ask. The form he chooses displays him (and his mother, on whose behalf he is making the request) as someone who is merely 'wondering if'; he avoids questioning the doctor's ability or willingness to help, which he could have done by using a modal verb.

When no response is forthcoming, he continues his request by questioning the very possibility (see line 22, example 16) that such a remedy exists and/or that it can be recommended or prescribed over the phone. In example 15 and other modal verb requests (see example 1), speakers orient to and claim the reasonableness of their request as grounds for expecting its granting. They may display evidence of their entitlement to make the request either before or after the request itself, or they may pointedly not orient to any possibility of the request not being granted. Given that there is a range of forms available, the use of any particular form is meaningful, and part of the function of the 
syntactic form selected is to display speakers' assessment of their entitlement to have a request granted.

Obviously, speakers' estimations of this entitlement will be associated with their social relationship with the request recipient. Additionally, overt reference to the contingencies surrounding a request's granting is more commonly found in requests made to shops or doctor's offices, where speakers often claim to be unsure of the proper procedures for making requests or display concern over the contingencies that might need to be satisfied before their requests can be granted, thus leading to the hypothesis that the social setting triggers the use of a certain type of request form. Unsurprisingly, however, issues of contingency and entitlement can also arise in everyday conversation among intimates, and when they do, a particular set of request forms are mobilized to display an orientation to them. Example 17 provides evidence that claims to entitlement are not inextricably tied to the (sociolinguistic) register of the interaction (i.e., intimate vs. institutional), and that speakers may change their estimation of their entitlement to make certain requests during the course of an interaction. In this interaction between a mother and a daughter, the daughter (Kat) changes the linguistic form of her request by degrees until reaching, finally, one of the most contingent: "would it be possible" (line 14).

(17) Field $x(C) 2: 1: 4$

1 Les: Anyway when d'you think you'd like to come home $\downarrow$ love.

$2 \quad($.

3 Kat: Uh:m (.) we:ll Brad's goin' down on Monday.

$4 \quad(0.7)$

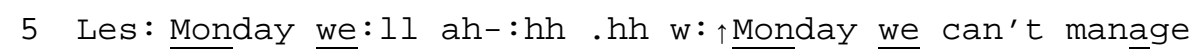

6 because (.) Granny's $\downarrow$ coming Monday. $\downarrow$

$7 \quad(0.4)$

8 Kat: 0 h; ,

$9 \quad(0.5)$

$\rightarrow 10$ Kat: Could- (๑.3)Dad $\uparrow$ couldn't pick me up from: : (.) ee- 


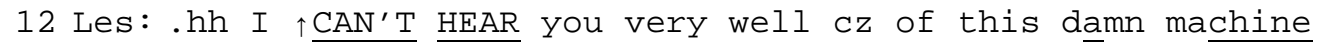
that's attached to this telephone $\uparrow$ say it again,

$\rightarrow 14$ Kat: Would it be possible: for Dad to pick me up from 15 Westbury on [Monday.

16 Les: $\quad$ [Ye:s yes $\uparrow \underline{\text { THAT }}$ would be $\downarrow$ alright

Lesley is questioning her daughter Kat about her plans to come home from university for christmas. Thus, the sequence shown here actually begins with Lesley's inquiry and Kat's response. Kat's somewhat indirect proposal - that she come home on Monday, the same day as her boyfriend Brad - is rejected by Lesley. Kat's subsequent request(s), beginning at line 10, proposes a different course of events. We must note, however, that this comes after Lesley withholds any suggestion of alternate plans: Kat provides an opportunity for her to do so in the 0.4 seconds that elapse at line 7 , as well as in the 0.5 seconds after 'oh'. Now Kat produces a request that is sequentially positioned after a rejection of her original proposal. It is also designed not to change the day she originally suggested (but has been the day her family "can't manage"). That is, in the turn at line 10, Kat doesn't amend the day she wants to come home; she merely suggests the place from which she could be picked up. ${ }^{9}$ Kat displays an orientation to the problematicity of this request by her choice of linguistic form. Her cut-off first word may have been only 'could', or she may have been beginning on the word 'couldn't'. At any rate, it is the form "couldn't" that she settles on to complete the request (line 10). This negative form begins to display a lack of certainty about her entitlement to make the request.

Finally, when responding to Lesley's repair initiation (line 12), Kat changes the form of her request to an even more contingent one: "would it be possible". The form of repair initiator selected by Lesley locates the prior turn as problematic; note also that Lesley specifically claims a problem in hearing (rather than understanding) as the trouble. Kat takes the opportunity provided by the other-initiation of repair (Schegloff, Jefferson \& Sacks 1977; 
Schegloff 2000) to change the syntactic format of her request. Rather than providing what was literally asked for - saying it again - Kat instead reveals an orientation to the problems evident in the sequence-so-far: first, her original response to her mother's inquiry was rejected as something "we can't manage". Second, her attempt at requesting an alternate plan be put into effect was treated as a trouble source, a treatment which is often the harbinger of (and in this case, another) dispreferred response such as a rejection or denial. Kat's selection of the request form "would it be possible" displays her nowdiminished estimation of entitlement to come home as and when she likes (see Lesley's original inquiry, line 1).

\section{CONCLUSIONS}

Speakers' choices of linguistic forms for making requests reflect their evaluation of the contingencies surrounding the granting of a request as well as their entitlement to make the request. By making a request using modal verbs and related forms, speakers treat their request as non-contingent; that is to say, they treat the conditions necessary for granting their request as fulfilled, and therefore their request as unproblematic. In contrast, in constructing requests using I wonder-prefaced formats, they orient to the contingencies which may be associated with the request (or more properly, with granting the request), contingencies which they may be unsure about (as for example when schedules, procedures or practices are not known).

In other words, callers' choice of request form makes a claim as to what they believe themselves reasonably entitled to, given the circumstances of the interaction, the item being requested, and/or the sequence in which the request is placed - rather than being a reflex tied to the objective "institutionality" of the interaction or their social identities. There is instead an intersection between the everyday and the institutional, between displays of entitlement and acknowledgement of the contingencies surrounding the granting of a request. By using conventionalized request forms (e.g., can/could you, I want X), callers 
claim the right to have their request granted whether in an everyday or an institutional setting. Conversely, it is not an institutional setting per se that triggers the use of more contingent forms (e.g., I wonder if, if possible); rather, callers construct themselves as potentially lacking entitlement through their use of these forms. An investigation of request forms in other so-called institutional corpora supports this claim. In 100 calls to the emergency police number in a major UK city, none of the callers made an I wonder-prefaced request (see also Zimmerman 1992). In calls to the non-emergency numbers of police in the same city, however, I wonder-prefaced requests are the most common form of request. Callers in emergency situations know (and display that they know) they are entitled to police action (Whalen \& Zimmerman 1990). On the non-emergency lines, however, callers are not sure how to proceed, and often claim not to know if their complaint is even a police matter -- their uncertainty arising from the diversity of services which can be accessed through non-emergency police numbers. This mirrors the pattern we find in the after-hours medical and everyday corpora. Callers in the everyday corpus both orient to and display their social relationships through the type of request form they choose - the more presumptuous or assuming forms used when the requester has (and can show) good reason for thinking his/her request reasonable and easily granted, and therefore more common among family members. The calls in this corpus made to various businesses also reflect this orientation, with attendant decreases in displays of certainty about their entitlement to the requested objects or activities. These different linguistic forms arise out of the callers' construal and display of themselves as particular social beings - intimates vs. customers, laypeople vs. professionals. The same constitution of self and expectations occurs in the after-hours medical calls, where callers orient to and display their status by generally avoiding request forms which presume entitlement, instead opting for I wonder-prefaced requests. Previous studies which have investigated the use of different request forms in naturally-occurring talk are Wootton (1981, 1997, 2005); Ervin-Tripp (1976); Heinemann (2006); Lindström (2005); Vinkhuyzen \& Szymanski (2005). Ervin-Tripp's investigation of directives 
in various social settings includes an analysis of the use of various request forms. She finds that the type of request form a speaker may use to perform a directive is systematically linked to, among other things, the "expected roles" of the interactants as well as "the seriousness or cost of the service asked, and whether compliance may be assumed because of the type of service, normal roles, or power relations" (p. 36-7).

Wootton's systematic, longitudinal studies of the request forms employed by a child finds ample evidence of the systematic selection of particular request forms from among a set of alternatives based on the child's displayed understanding of the sequential implications of prior talk. Wootton (2005) demonstrates that there is a distributional difference in the deployment of the 'can you' request form, which is used "where the recipient is being treated as having a basis for expecting a course of events to unfold in a different way to what they are now being requested to do." (p. 204), but not in other environments (such as when the child proposes an activity in keeping with the activity-so-far, or when the child's request displays an overt opposition to the projectable next activity). Our description of the use (and avoidance of) modal forms and the I wonder preface parallels the work of both these researchers, in the way that speakers' choice of one form over another displays their assessment of the contingencies involved as well as their entitlement to the requested object.

Politeness, as noted in the introduction, is, a commonly invoked explanation for the use of different (indirect) request forms. In light of our findings, its explanatory power seems lacking. It is difficult to say which form is more polite: 'could you' or 'I wonder if you could'. Both are indirect, and additionally, we cannot find 'I wonder if' listed as a request form in any published reports of measures of politeness - in fact the only place we find it cited in the literature as a request form is in Searle (1975:64). And while restricted, its use in our corpora is not oriented to as bizarre or unusual. Indeed, asserting the relative politeness of an utterance amounts to little more than applying a label drawn from past judgements made about similar 
constructions. We can and do show that speakers orient to the appropriateness of certain forms, based on the particulars of the situation, including the sequence of talk in which the form is embedded. Politeness theory, however, rests on inferences about speaker intent drawn by a hearer, and therefore cannot make any predictions about what form we can expect to find where.

Our findings concerning the association between request forms and speakers' orientations to contingency are congruent with the findings of Lindström(2005) and Heinemann (2006), and of Vinkhuyzen \& Szymanski (2005). Lindström and Heinemann each show that the selection between different request forms - imperatives, or interrogatively formed requests (as in 'Do you have the time to. . . ?' $^{\prime}$, in Lindström's study of a Swedish home help service; and positively or negatively formed interrogative constructions ('Will you. . . ? vs Can't you. . . ?) in Heinemann's study of a similar service in Denmark - embody different stances regarding whether or not speakers are entitled to make the request. Furthermore, Vinkhuyzen \& Szymanski (2005) show that customers' selection between forms such as 'I need. . .' and 'Can you make. . . ?' are associated with their knowledge of whether the organisation (a copy shop) provides the particular service they are requesting, which in turn may be related to customers' relative expertise. Our comparative approach, investigating the differential distributions of what we found were the most frequently used syntactic forms for requesting in our different corpora, consolidates the pattern emerging from these studies, that by selecting one from alternative forms for requesting, speakers display different stances towards the 'grant-ability' of what is requested. However, in our study contingency emerges as the dimension which underlies entitlements to ask, the ease with which the recipient might grant the request, whether a particular service is offered/can be provided, and all such other factors which are salient to 'grant-ability'. 


\section{REFERENCES}

Austin, J. L. (1962). How to Do Things with Words. Cambridge, Mass.: Harvard University Press.

Blum-Kulka, S. (1987). Indirectness and politeness in requests: same or different? Journal of Pragmatics, 11(1): 131-146.

Brown, P., \& Levinson, S. C. (1987). Politeness: Some Universals of Language Usage. Cambridge: Cambridge University Press.

Clark, H. H. (1979). Responding to indirect speech acts. Cognitive Psychology, $11,430-477$.

Clark, H. H. \& Schunk, D.H.. (1980). Polite responses to polite requests. Cognition, 8, 111-143.

Curl, T. S. (2006). Offers of assistance: Constraints on syntactic design. Journal of Pragmatics, 38, 1257-1280.

Curl, T.S., Drew, P., \& Ogden, R. (forthcoming). Language and Social Action. Cambridge: Cambridge University Press.

Drew, P. (2005). Conversation analysis. In Kristine Fitch \& Robert Sanders (Eds.) Handbook of Language and Social Interaction (pp.71-102). New Jersey: Lawrence Erlbaum.

Drew, P. (2006). Mis-alignments between caller and doctor in 'out-of-hours' telephone calls to a British $\mathrm{GP}^{\prime}$ s practice. In J. Heritage \& D. Maynard (Eds.) Communication in Medical Care: Interaction between Primary Care Physicians and Patients (pp. 416-444). Cambridge: Cambridge University Press.

Ervin-Tripp, S. (1976). Is Sybil there? the structure of some American English directives. Language in Society, 5, 25-66.

Francik, E P. \& Clark, H.H. (1985). How to make requests that overcome obstacles to compliance. Journal of Memory and Language, 24, 560-568.

Gibbs, R. W. (2002). A new look at literal meaning in understanding what is said and what is implicated. Journal of Pragmatics, 34, 457-486.

Gill, V. T., Halkowski, T. \& Roberts, F. (2001). Accomplishing a request without making one: A single case analysis of a primary care visit. Text, 21, 55-81. 
Grice, P. (1975). Logic and conversation. In P.Cole \& J.L.Morgan (Eds.) Syntax and Semantics, vol.3: Speech Acts (pp. 41-58). New York: Academic Press. Heinemann, T. (2006). 'Will you or can't you?' Displaying entitlement in interrogative requests. Journal of Pragmatics, 38, 1081-1104. Heritage, J. (1984). Garfinkel and Ethnomethodology. Cambridge: Polity Press. Hopper, P. (1987). Emergent grammar. In Proceedings of the Berkeley Linguistics Society, vol. 13 .

House, J. \& Kasper, G. (1981). Politeness markers in English and German, In F. Coulmas (Ed.) Conversational Routine (pp. 157-185). The Hague: Mouton. Lerner, G. (1996). 'Finding face' in the preference structures of talk-ininteraction. Social Psychology Quarterly, 59, 303-321

Lindström, A. (2005). Language as social action: A study of how senior citizens request assistance with practical tasks in the Swedish home help service. In A. Hakulinen \& M. Selting (Eds.) Syntax and Lexis in Conversation (pp. 209233). Amsterdam: John Benjamins .

Pawley, A. \& Hodgetts Syder, F. (1983). Natural selection in syntax: Notes on adaptive variation and change in vernacular and literary grammar. Journal of Pragmatics, 7, 551-579.

Perkins, M. R. (1983). Modal Expressions in English. London: Frances Pinter. Sacks, H. (1992). Lectures on Conversation (Volume II). Edited by G. Jefferson. oxford: Blackwell.

Schegloff, E. A. (1979). The relevance of repair to syntax-for-conversation. In T. Givón (Ed.) Syntax and Semantics 12: Discourse and Syntax (pp. 261-286). London: Academic Press.

Schegloff, E. A. (1988a). Pre-sequences and indirection: applying speech act theory to ordinary conversation. Journal of Pragmatics, 12: 55-62.

Schegloff, E. A. (1988b). On an actual virtual servo-mechanism for guessing bad news: a single case conjecture. Social Problems, 35(4), 442-473.

Schegloff, E. A. (1990). On the organization of sequences as a source of 'coherence' in talk-in-interaction. In B. Dorval (Ed.) Conversational Organization and its Development (pp. 51-77). Norwood, NJ: Ablex. 
Schegloff, E. A. (1993). Reflections on quantification in the study of conversation. Research on Language and Social Interaction 26(1), 99-128. Schegloff, E. A. (1996). Turn organization: One intersection of grammar and interaction. In Elinor Ochs, Emanuel A. Schegloff \& Sandra A. Thompson (eds.) Interaction and Grammar. (pp. 52-133). Cambridge: Cambridge University Press. Schegloff, E. A. (2000). When 'others' initiate repair. Applied Linguistics, 21, $205-243$

Schegloff, E. A. (2006). Sequence Organization in Interaction: A Primer in Conversation Analysis. Cambridge: Cambridge University Press.

Schegloff, E. A., Jefferson, G. \& Sacks, H. (1977). The preference for selfcorrection in the organization of repair in conversation. Language 53(2), $361-382$.

Searle, J. R. (1975). Indirect speech acts. In P. Cole \& J. L. Morgan (Eds.) Syntax and Semantics 3: Speech Acts. (pp. 261-286). New York: Academic Press. Upadhyay, S. R. (2003). Nepali requestive acts: Linguistic indirectness and politeness reconsidered. Journal of Pragmatics, 35, 1651-1677. Vinkhuyzen, E. \& Szymanski, M.H. (2005). Would you like to do it yourself? Service requests and their non-granting responses. In K. Richards \& $\mathrm{P}$. Seedhouse (Eds.) Applying Conversation Analysis (pp. 91-106). New York: Palgrave Macmillan.

Watts, R. J. (2003). Politeness. Cambridge: Cambridge University Press. Whalen, M. \& Zimmerman, D.H. (1990). Describing trouble: practical epistemology in citizen calls to the police. Language in Society, 19, 465-492.

Wootton, A. J. (1981). Two request forms of four year olds. Journal of Pragmatics, 5, 511-523.

Wootton, A. J. (2005). Interactional and sequential features informing request format selection in children's speech. In A. Hakulinen \& M. Selting (Eds.) Syntax and Lexis in Conversation (pp. 185-207). Amsterdam: John Benjamins. Zimmerman, E. H. (1992). The interactional organization of calls for emergency assistance. In P. Drew \& J. Heritage (Eds.) Talk at Work (pp. 418-469). Cambridge: Cambridge University Press. 
APPENDIX: TRANSCRIPTIONS

\author{
The transcriptions which appear in this paper are edited versions of those \\ prepared by Gail Jefferson (and other, unknown transcribers). Although these \\ conventions are quite helpful as aides memoire when one has heard the talk they \\ represent, it should be remembered that transcripts are offered as a particular \\ representation of the talk, not as the data. All analyses in this paper were \\ carried out using the audio recordings in tandem with the written representation \\ of the talk. At times, non-standard spellings are used to reflect the speed \\ and/or syllable reduction of the talk, but these have been reduced to a minimum \\ to enhance readability.
}

1 We think that it's pretty widely accepted now that, as Watts notes, Can/could you do $X$ has become the unmarked form for requesting (Watts 2003:193) - conventionally a standard way to make a request directly. So that the distinction between Would you... and Could you.... is of relatively minor significance (except as a resource for wisecracks).

2 The tense of wonder may be significant in these contexts. The literature is somewhat loose on this point: Watts, quoting House and Kasper, refers only to past tense (I wondered if...) and progressive aspect with past tense (I was wondering...) (Watts 2003: 183 and 196). But these, again, are hypothetical or made-up examples. All the cases that we have found in our data are simple present tense, I wonder if... .

3 The first published reference we can find to requests as dispreferred first actions is this: “...in the case of requests, which may themselves not be the preferred way of acquiring some object or service, the prerequest can make possible an offer...” (Schegloff 1990: 63). This claim is developed in Lerner 1996: 314-316) and most recently Schegloff 2006:chap. 5. The evidence for regarding request as dispreferred initial actions is, in our view, at least equivocal. For instance, Lerner shows that, anticipating where a speaker is 'going' with some preliminaries and that they want something, recipients may step in and offer what they take it the other wants. He cites this example (Lerner 1996: 315):

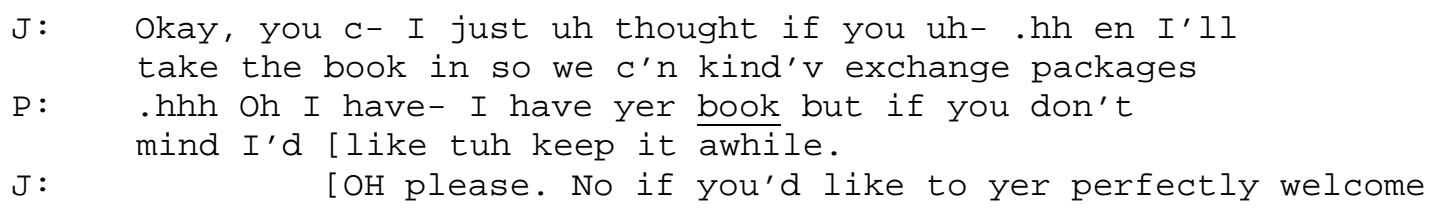

Lerner comments that the anticipatory completion - designed to interrupt the emerging action by $\mathrm{P}$ - in which $\mathrm{J}$ offers that P should keep the book (last line of extract) is evidence for the preference for offers, and dispreference for requesting. But this flies in the face of the fact that $\mathrm{P}$ continues in the overlap through to completion of her request ; that is, they persist unnecessarily with their request (the other example Lerner shows as similar evidence has precisely the same feature, ie. that the request is carried through to completion, in overlap with the other's offer). If a request were indeed a dispreferred action, then the speaker who wants something has every opportunity to halt the progress of his/her request, at or close after the point at which the other begins in overlap with their offer.

4 In Britain, patients register with a primary care physician, which generally means the doctor in charge of the office closest to the patient's home. Each doctor's office has an after-hours line which patients may call with medical queries that do not seem (initially at least) to warrant a trip to the emergency room. A doctor may then either give advice for self-treatment, offer to visit the patient at home, or recommend that the patient go immediately for 
emergency treatment.

5 Imperatives, negative interrogatives and 'I want' formulations (which are treated as requests by the recipient) account for the remaining one third of the collection. These request formats are, in a sense, just what we would expect to find, and represent part of the continuum (see Curl, Drew and Ogden forthcoming) of the syntactic formats of requests (see also Lindström (2005), Heinemann (2006)). Early research into requests and indirectness recognizes these forms (save imperatives) as conventional request forms (e.g., Searle 1975; Ervin-Tripp 1976). Though imperatives are comparatively rare in the telephone data, some of the videotaped dinnertime interactions we are currently analyzing show that the use of imperatives is tied to the same issues of entitlement and contingency we identify here. The notuncommon production of imperatives as requests additionally seems to contrast with the prevailing explanation that 'politeness' informs speakers' choice of request form.

6 There are altogether 39 requests, but some are subsequent formulations of requests for assistance with the same problem. No second productions of a request are done with an I wonder preface.

$7 \quad$ The next largest group of linguistically explicit requests are those in which callers specify that they want advice from the doctor without using an I-wonder preface, yet there are only half as many of these as of I wonderprefaced requests.

$8 \quad$ While there may indeed be some relationship between the objective circumstances of a caller's situation and their subjective claim to need help, it is not easily discernable in the after-hours medical corpus. Some callers report what seem to be serious problems - a 83-year-old unable to keep food or drink down for more than 3 days; an asthmatic child having continued difficulty in breathing after the administration of medicine - but they themselves do not treat them as such (see also Gill, Halkowski \& Roberts 2001:57 on the delicacy of patients doing the doctor's work of diagnosis). The callers in examples 7-17, however, do portray the situation as recognizably serious and doctor-able (even doctor-necessary) both through the way they describe the problem and the way they format their requests to display expectations of entitlement. This stands in contrast to the majority of request calls in the after-hours medical corpus which merely 'wonder if' help is available.

$9 \quad$ Kat is suggesting that her father collect her from a town nearby to her home, rather than collect her from the city where she is away at university. 